\title{
Trend of sputum smear positivity among presumptive tuberculosis cases visiting respiratory disease centre of Western Maharashtra, India
}

\author{
HS Sidhu ${ }^{1}$, Shishir Jain ${ }^{2, *}$, Ashish Bahal ${ }^{3}$, Himanshu Sharma ${ }^{4}$ \\ ${ }^{1,3}$ Assistant Professor, ${ }^{1,3}$ Dept. of Pathology, Military Hospital CTC, Pune, Maharashtra, ${ }^{2}$ Assistant Professor, ${ }^{4}$ Resident, ${ }^{2,4}$ Dept. \\ of Community Medicine, Armed Forces Medical College, Pune, Maharashtra, India
}

*Corresponding Author:

Email: shishirjainpro@gmail.com

\begin{abstract}
Introduction: India amounts to about a quarter of the tuberculosis (TB) burden worldwide. In 2016 about 28 lakh cases occurred and 4.5 lakh people died due to TB. In March 2017 the Government of India (GoI) declared that the new aim for TB in India was the elimination of TB by 2025.

Objectives: To estimate the trends and gender distribution of sputum smear positive tuberculosis among presumptive TB cases visiting respiratory disease centre of Western Maharashtra.

Materials and Methods: A Record based cross sectional study was conducted in a respiratory disease centre of Western Maharashtra, India during Jan 2018. All registered patients suspected of TB visiting the respiratory disease centre from year 2013 to 2017 were included as study population. Patients having incomplete data were excluded from study. Data was collected from master register at department of pathology of respiratory disease centre and was compiled and entered into MS Excel 2007. The trend of case detection, gender and TB, Sputum positive / negative cases were analyzed. The trend was statistically analysed for 2013-2017 by using chi - square test for trend. Trend was considered significant if $\mathrm{p}$ value is less than 0.05 .

Results: Among total suspected cases, proportion of sputum positive cases showed upward trend of TB from year 2013 to 2015 but thereafter linear downward by 2017. Out of total sputum smear positive cases $94.12 \%$ were males and $5.88 \%$ were females.

Conclusion: Data indicates that tuberculosis is a great challenge in Western Maharashtra, India and need to strengthen the awareness programme about TB and involvement of public private partnership, early case detection and adherence with treatment to control the burden of TB.
\end{abstract}

Keywords: Pulmonary tuberculosis, Sputum smear positivity, Trends, Gender.

\section{Introduction}

Tuberculosis (TB) is a global disease in spite of the fact that the etiological agent was discovered more than 100 years ago. TB is a major public health problem amounting to catastrophic social and economic cost. According to WHO count of new cases of tuberculosis was 8.6 million and mortality of 1.3 million. ${ }^{1}$ By year 2020, the global burden of TB may reach beyond one billion with more than $80 \%$ disease burden could be from the low income countries. ${ }^{2,3}$ WHO has developed a TB- Sustainable Development Goal (SDG) monitoring framework that comprises 14 indicators under seven SDGs which is related with TB incidence. ${ }^{4}$

Around thirty five percent of the world population is infected asymptomatically with TB of which five to ten percent will develop clinical disease in their entire life span.

The efficacy of the laboratory test to diagnose sputum positivity is dependent entirely on the quality and quantity of sputum sample tested. There are no defined guidelines discussing merits or demerits of different sputum collection methods. The different methods available are spot sputum collection, pooled sputum and induced sputum. Preferably induced early morning pooled sample is the most preferred one. However because of the difficulty in getting early morning sample, the spot sample collection is preferred. The samples which are collected are subjected to microscopy and this sample will be positive if and only if the concentration of Acid fast bacilli exceeds $10,000 / \mathrm{ml}$ of the sample. Early morning sputum collection is a hindrance as this requires an additional trip to the diagnostic facility and may at times not be logistically feasible.

In 2016, an estimated 28 lakh cases occurred and 4.5 lakh people died due to TB. ${ }^{4}$ According to a report by MOHFW in 2013, TB remains a major public health challenge in India and accounts for one fourth of the estimated global incidence of TB cases. ${ }^{5,6}$ Every year in the India nearly 1.5 to 1.8 million people develop TB and about 8 lakh is the incidence of sputum smearpositive cases. About 2.8 lakh people die of TB every year $^{7}$ reasons being poverty, illiteracy, malnutrition, inadequate health care services, and attitude of community, traditional medical practices and burden of HIV-AIDS infection. TB affects people in their most productive years of life.

Gender is an important variable in infectious disease epidemiology. A 1998 review $^{8}$ on gender differences in TB suggested that women in low-income countries were probably under notified. According to Government of India (2010), TB India 2010 report around sixty five percent of the cases are male but TB takes a big toll in young females and around fifty percent of morbidity is before the age of thirty four years. In March 2017 the Government of India (GoI) announced that the new aim for TB in India was the elimination of TB by $2025 .{ }^{9}$ 
Considering all this, the present study aimed to assess the trends of sputum smear positive tuberculosis and gender distribution among patients visiting a respiratory disease centre of Western Maharashtra.

\section{Materials and Methods}

A record based cross sectional study was conducted in a respiratory disease centre of Western Maharashtra, India during Jan 2018. All registered patients suspected of TB visiting the respiratory disease centre from year 2013 to 2017 were included as study population. It is one of the biggest and leading respiratory disease centre in the Western Maharashtra. Patients having incomplete data were excluded from study. Ziehl-Neelsen stain was used for staining Mycobacterium tuberculosis bacteria. Although Lowenstein-Jensen medium is golden standard in cases of tuberculosis, acid fast bacilli staining is well recommended by WHO. Demonstrating the acid fast bacilli by using Ziehl-Neelsen stain is the most affordable method in Low and Middle Income Countries (LMIC). Ziehl-Neelsen staining is also a recommended tool in the management of TB as per the strategies mentioned by WHO. The Ziehl-Neelsen stain (acid-fast stain) was described by two German doctors: the bacteriologist Franz Ziehl (1859-1926) and pathologist Friedrich Neelsen (1854-1898). It is a special stain used to identify acid-fast organisms, mainly Mycobacteria (Mycobacterium tuberculosis). Data was collected from master register at Department of Pathology of respiratory disease centre and was compiled and entered into MS Excel 2007. The trend of case detection, gender and TB, Sputum positive / negative cases were analyzed. Statistical Package for Social Sciences (SPSS) version 20 statistical software was used for analysis. Association between variables was calculated by using chi-square test. The trend was statistically analysed for 2013-2017 by using chi square test for trend. Trend was considered significant if $\mathrm{p}$ value is less than 0.05 .

\section{Results}

A total of 9545 patients suspected of tuberculosis were registered in respiratory disease centre of Western Maharashtra during the year 2013 to 2017. (Table 1)

Table 1: Distribution of the study population as per gender $(\mathrm{N}=9545)$

\begin{tabular}{|l|c|c|c|}
\hline Year & Male & Female & Total \\
\hline & $\mathbf{n}(\boldsymbol{\%})$ & $\mathbf{n}(\boldsymbol{\%})$ & $\mathbf{n}(\boldsymbol{\%})$ \\
\hline 2013 & $2010(92.96)$ & $152(07.04)$ & $2162(22.65)$ \\
\hline 2014 & $2027(98.00)$ & $68(02.00)$ & $2095(21.95)$ \\
\hline 2015 & $1685(96.67)$ & $58(03.33)$ & $1743(18.26)$ \\
\hline 2016 & $1967(97.23)$ & $56(02.77)$ & $2023(21.19)$ \\
\hline 2017 & $1459(95.90)$ & $63(04.10)$ & $1522(15.95)$ \\
\hline & $9148(95.80)$ & $397(04.20)$ & $9545(100.00)$ \\
\hline
\end{tabular}

Chi square value $=61.9, \mathrm{p}$ value $<.001$

Table 2: Gender and sputum smear positivity

\begin{tabular}{|l|c|c|c|}
\hline Gender & Sputum smear positive & Sputum smear negative & Total \\
\hline & $\mathbf{n}(\boldsymbol{\%})$ & $\mathbf{n}(\boldsymbol{\%})$ & $\mathbf{n}(\boldsymbol{\%})$ \\
\hline Male & $733(08.00)$ & $8415(92,00)$ & $9148(100)$ \\
\hline Female & $45(11.30)$ & $352(88.70)$ & $397(100)$ \\
\hline Total & $778(08.20)$ & $8767(91.80)$ & $9545(100)$ \\
\hline
\end{tabular}

Chi square value $=5.61, \mathrm{p}$ value $=.018$

Proportion of female sputum smear positive cases was higher $(11.3 \%)$ as compared to males $(08 \%)$. Out of total sputum smear positive cases $94.21 \%$ were males and $5.78 \%$ were females. (Table 2)

Among total suspected cases, proportion of sputum positive cases showed upward trend of TB from year 2013 to 2015 but thereafter, linear downward trend till 2017. (Fig. 1) 


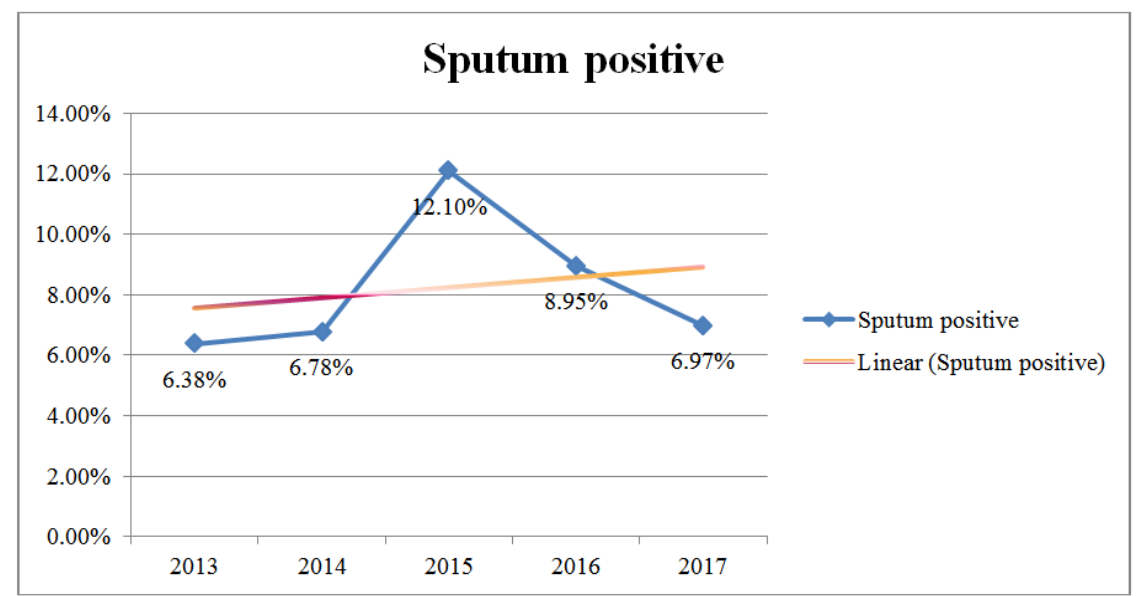

Chi square value $=5.195, \mathrm{p}$ value $=0.022$

Fig. 1: Trend of sputum smear positive cases

Among the sputum smear positive cases, proportion of strongly positive cases (1-9 or $>9$ AFB seen per field at $1000 \mathrm{X}$ magnification) showed periodic fluctuations over 5 years of study period with maximum and minimum proportion reported for year 2014 and 2016 respectively. (Fig. 2)

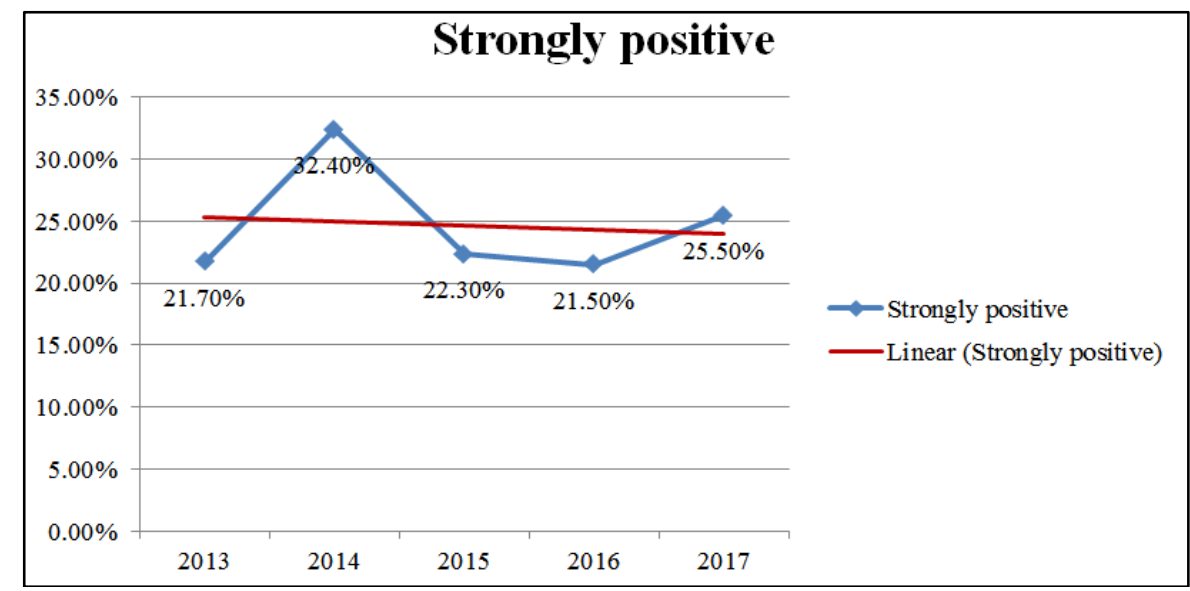

Chi square value $=0.262$, $\mathrm{p}$ value $=0.61$

Fig. 2: Trend of strongly sputum smear positive cases

\section{Discussion}

The present record based evaluation study conducted in Western Maharashtra, India since year 2013 to 2017 has been shown the upward trend of TB from year 2013 to 2015 but thereafter linear downward by 2017 . The high difference in incidence of TB was mainly due to lack of adequate infrastructure, population explosion and poverty. Findings reported by Government of India shows that incidence of TB has reduced from 289 per lakh per year in 2000 to 217 per lakh per year in 2015 and the mortality due to TB has reduced from 56 per lac per year in 2000 to 36 per lac per year in $2015 .^{10} \mathrm{~A}$ similar study done in Maharashtra displayed previous five years trend from year 2008 to 2012 and showed upward trend from 2008 to 2010 but linear downward trend from 2010 to $2012 .{ }^{11}$ A similar linear downward trend is noted from year 2015 to 2016 in study done in North India. ${ }^{12}$ The decrease in the sputum smear positive TB could be related to the success of TB control strategy.

Opposite trend was reported from a study done in Ghana showing increase in sputum smear positive pulmonary TB from 2013 to $2016 .{ }^{13}$ This could be due to ineffective strategies and TB control programme. TB was declared as an emergency in Africa in 2005 when the annual incidence increased four time in African countries from the 1990 incidence and continues to rise, killing more than half a million every year. ${ }^{14}$

In our study, out of total sputum smear positive cases $94.12 \%$ were males and $5.88 \%$ were females and same trend was reported in earlier study in Maharashtra. ${ }^{11}$ Studies done in India shows similar gender distribution pattern having a wide sex gap with male patients outnumbering female patients. ${ }^{15,16}$ Our study findings are in agreement with gender distribution studies done in Zimbabwe ${ }^{17}$ and Malawi. ${ }^{18}$

Women often remain under-notified by public health authority and undiagnosed female host may 
serve a potential source of latent infection. This could be related to more males having propensity to visit hospitals when they do have problem or have much more close social network and gatherings to inherit the disease than females. In many communities women are employed in work outside the home in the domestic or agriculture sector to provide household income. TB in women leads to loss of work and income. ${ }^{19}$

Among the sputum smear positive cases, proportion of strongly positive cases showed periodic fluctuations over 5 years of study period.

Limitation: Limitation of the study is that being a hospital based study; results cannot be extrapolated to the entire community.

\section{Conclusion}

Data showed that tuberculosis is a great challenge in Western Maharashtra and there is a need to intensify the awareness programme about $\mathrm{TB}$, involvement of public private partnership, early case detection and adherence with treatment to control the burden of TB. Efforts to increase the gender sensitivity of health services and to promote community awareness of TB should be there. Health education through Information, Education and Communication (IEC), motivation for early detection, BCG immunization for children, removal of stigma, regular drug intake and follow up are some of the measures which can decrease the morbidity and mortality due to TB.

The molecular and cultural methods which are available for diagnosis although have higher sensitivity but are not economically viable in a third world country for population based diagnostic services. It is therefore imperative that sample collection is the cornerstone of sputum testing. There are no universal guidelines available to enhance the sensitivity of sputum testing based on methods of sputum collection.

Resistant TB is again becoming big problem to India and considering this TB has been declared as a notifiable disease in year 2012 by Government of India. Targets for reductions in TB incidence according to WHO's End TB Strategy and the United Nations' Sustainable Development Goals (SDGs) are ambitious. Achieving them requires reduction in health-related risk factors for TB infection and disease, as well as in social and economic determinants. WHO has developed a TBSDG monitoring framework that comprises 14 indicators under seven SDGs which is related with TB incidence.

\section{References}

1. The World Health Organization monitors the global tuberculosis epidemic in support of national TB control programmes [Internet]. Global Tuberculosis Control WHO REPORT. 2010. www.who.int/tb.

2. Lal S. Tuberculosis. Textbook of Community Medicine. New Delhi: CBS Publishers; 2014; p. 435-442.
3. World Health Organization. Global Tuberculosis Control: Surveillance, Planning, Financing. WHO Report 2002. Geneva, Switzerland, WHO/CDS/TB/2002.295.

4. World Health Organization. Global Tuberculosis Report 2017: Leave no one behind - Unite to end TB [Internet]. 2017. $146 \mathrm{p}$.

http://www.who.int/tb/publications/global_report/gtbr201 7.

5. Central TB Division. TB India 2013.Pdf [Internet]. 2013. p. 2-223. www.tbcindia.

6. Donald PR, van Helden PD. The Global Burden of Tuberculosis - Combating Drug Resistance in Difficult Times. N Engl J Med [Internet]. 2009;360(23):2393-5. Available from: http://www.nejm.org/doi/abs/10.1056/NEJMp0903806.

7. Suryakantha AH. Epidemiology of communicable disease. Community Medicine with recent advances. New Delhi: Jaypee publication; 2010;p. 330-345.

8. Holmes CB, Hausler H, Punn P. A Review of sex differences in the epidemiology of Tuberculosis [Internet]. Vol. 2, International Journal of Tuberculosis and Lung Disease. 1998. p. 96-104.

9. TB Statistics India - National, treatment outcome \& state statistics. https://www.tbfacts.org/tb-india/ 2017.

10. Ministry of Health and Family Welfare. TB India 2017: RNTCP Annual Status Report. RNTCP Annual Status Rep [Internet]. 2017;1-173. http://www.tbcindia.nic.in/WriteReadData/TB India 2017.pdf.

11. Mohite RV, Ganganahalli PG, Lale SV Trend of tuberculosis and performance evaluation of new sputum positive tuberculosis from Satara district, 2015;6(1):2-7.

12. Wani A, Zahoor D, Shah S, Wani Y, Dar I, Ali S et al. Trends and Characteristics of Smear Positive Pulmonary Tuberculosis in a Tertiary Care Hospital In North India. Int J Adv Res. 2017;5(8):1445-9.

13. Osei FA, Enimil A, Ansong D, Laryea DO, Mensah NK, Amuzu EX, et al. Review of Organism Density and Bacteriologic Conversion of Sputum among Tuberculosis Patients. 2017: 2017:1-6.

14. World Health Organization. WHO declares TB an emergency in Africa 2005. http://www.who.int/mediacentre/news/releases/2005/afric a emergency/en/.

15. Prakasha R, Suresh G, Peter I, Kumar S, Rao R.A study of clinical characteristics and trend of different types of tuberculosis in coastal South India. Ann Trop Med Public Health 2012;5:489-94.

16. Mukherjee A, Sarkar A, Saha I, Chowdhury R. Gender differences in notification rates, clinical forms and treatment outcome of tuberculosis patients under the RNTCP. Lung India [Internet]. 2012;29(2):120. http://www.lungindia.com/text.2012/29/2/120/95302.

17. Noppert G, Yang Z, Sandy C, Chirenda J. Trends of sputum-smear positive tuberculosis in Zimbabwe: 20082011 Public Health. BMC Research Notes. 2015 Oct 16;8(1). 575. DOI:10.1186/s13104-015-1568-z.

18. Boeree MJ, Harries AD, Godschalk P, Demast Q, Upindi B, Mwale A et al. Gender differences in relation to sputum submission and smear-positive pulmonary tuberculosis in Malawi. Int $J$ Tuberc Lung Dis. 2000;4(9):882-884.

19. R. Elliot, Press Release: New Toolkit Helps Chinese Companies Tackle Tuberculosis Head On, Davos, World Economic Forum, 2008. http://www. lillymdrtb.com/pr/WEF_26_Sept08_En.pdf. 